\title{
El acoso laboral: ENTRE El DERECHO Y LA PSICOLOGÍA
}

["Harassment at Work: Between Law and Psychology"]

\author{
José Luis UGarte* \\ Universidad Diego Portales, Santiago de Chile
}

\begin{abstract}
RESUMEN
La adopción de la figura del acoso laboral en el Derecho del trabajo ha sido difícil y paulatina, debido particularmente a que el concepto proviene de una disciplina ajena al mundo legal, la Psicología. Este trabajo hace una revisión de la recepción de dicha noción en los ámbitos legal, jurisprudencial y doctrinal y en la experiencia comparada.
\end{abstract}

\section{Palabras Clave}

Acoso laboral - "Mobbing" - Lesión a los derechos fundamentales del trabajador.

\begin{abstract}
Adopting the construct of harassment in Labor Law has been a hard and gradual task, particularly given that this concept comes from Psychology, a discipline that is not related to the legal world. This work revises how this concept has been received within the legal, jurisprudential and doctrinal scopes, as well as in the compared experience.
\end{abstract}

\section{KEYWORDS}

Harassment at work - Mobbing Damage to the fundamental rights of the worker.

RECiBIDo el 29 de agosto y ACEPTADo el 6 de octubre de 2012.

* Profesor de Derecho del trabajo de la Universidad Diego Portales. Dirección postal: Avenida República 112, Santiago, Chile. Correo electrónico: jose.ugarte@udp.cl. Este artículo es parte del Proyecto Fondecyt regular No 1110457: "El acoso moral o "mobbing" y la acción de tutela en la nueva justicia laboral". El autor agradece la ayuda en su elaboración de Orielle Ahumada y María Jesús Porter. 


\section{Recepción Del CONCEPTO De ACoso laboral EN EL DeRecho}

La figura del acoso laboral ya no es desconocida para el Derecho del trabajo. Progresivamente se ha ido incorporando al horizonte jurídico la noción de acoso moral en el trabajo, "mobbing" o acoso laboral, ya sea de la mano del legislador, de la jurisprudencia o de la doctrina.

Eso sí, a diferencia de otras figuras, como el acoso sexual, se trata de una recepción fundamentalmente articulada desde la doctrina y la jurisprudencia. Salvo contadas excepciones, el acoso laboral no ha sido objeto de incorporación legislativa expresa en los diversos ordenamientos jurídicos laborales analizados por los informes. En ese sentido, la recepción de la figura está generalizada -prácticamente no existen experiencias comparadas relevantes que no la contemplen-, pero sólo por excepción a través de la dictación de preceptos legales sobre la figura.

De este modo, en primer lugar, están aquellos escasos países donde el Derecho del trabajo habilita legalmente la figura: el legislador ha incorporado, ya sea en normas comunes o en normas específicas sobre seguridad o salud en el trabajo, la noción de acoso laboral. Es el caso de Colombia, Francia y recientemente Chile.

En segundo lugar, se encuentran los países, en número mayoritario, donde el Derecho del trabajo no contempla una recepción explícita en la ley del acoso laboral, pero dicha figura se ha venido construyendo por otras fuentes del derecho, especialmente la jurisprudencia y por la doctrina científica.

En tercer lugar, existen algunas tradiciones jurídicas donde el concepto de acoso laboral está, además, vinculado a la discriminación y a la violencia contra las mujeres. En Rumania, el artículo 4 de la Ley $\mathrm{N}^{\circ} 202$, del año 2002, que establece normas antidiscriminatorias, entiende por acoso un comportamiento no deseado relacionado con el sexo de la persona, que tenga por objeto o efecto dañar la dignidad de la persona y crear un ambiente de intimidación, hostil, degradante o humillante. A su turno, en la República Checa el "mobbing" se reconoce en la Ley No 198/2009, sobre igualdad de trato y sobre los medios jurídicos de protección contra la discriminación, y se le define como: "un comportamiento no deseado, relacionado con motivos discriminatorios (raza, origen étnico, nacionalidad, sexo, orientación sexual, edad, deterioro de la salud, credo, religión y creencias politicas), con la intención o la consecuencia de reducir la dignidad de una persona y la creación de trabajo intimidante, hostil, degradante, humillante u ofensivo, o que pueda ser razonablemente entendida como una condición previa para una decisión de influir en el ejercicio de los derechos y obligaciones derivados de las relaciones juridicas".

Del mismo modo, en España, el artículo 7 de la Ley $N^{\circ}$ 51/2003 considera 
acoso toda actitud dirigida a las personas con minusvalía que tenga "como objetivo o consecuencia atentar contra su dignidad o crear un entorno intimidatorio, hostil, degradante u ofensivo". A su vez, el art. 28 de la Ley $\mathrm{N}^{\circ} 62 / 2003$, que transpone al ordenamiento jurídico español la Directiva 2002/73/CE de 23 de septiembre sobre el principio de igualdad entre hombres y mujeres, incorpora una mención al acoso definiéndolo como una "conducta no desea$d a$ " en situaciones en las que la víctima lo sea por su "origen racial o étnico, religión o convicciones, discapacidad, edad u orientación sexual".

En otra vinculación especialmente interesante, se encuentran aquellos ordenamientos jurídicos que, pese a no tener una figura expresa y general de acoso laboral, la misma ha sido reconocida parcialmente por las normas que sancionan la violencia contra las mujeres. En Argentina, la Ley $\mathrm{N}^{\circ} 26.485$, de protección integral para prevenir, sancionar y erradicar la violencia contra las mujeres en los ámbitos en que se desarrollen sus relaciones interpersonales (BO. 14 de abril de 2009) define a la violencia contra las mujeres como: "toda conducta, acción uomisión que, de manera directa o indirecta, tanto en el ámbito público como en el privado, basada en una relación desigual de poder, afecte su vida, libertad, dignidad, integridad física, psicológica, sexual, económica $y / o$ patrimonial, como asítambién su seguridad personal". Se incluye, como señala el informe argentino, como una de las formas de violencia laboral al hostigamiento psicológico en forma sistemática sobre una determinada trabajadora con el fin de lograr su exclusión social (art. 6 de la Ley No 26.485). Otro tanto ocurre en Venezuela, donde el régimen de represión de la violencia de género, contiene la previsión del acoso en el artículo 15.2 de la Ley orgánica sobre el derecho de las mujeres a una vida libre de Violencia, la que dice: "se consideran formas de violencia de género en contra de las mujeres, las siguientes: [...] Acoso u hostigamiento: Es toda conducta abusiva y especialmente los comportamientos, palabras, actos, gestos, escritos o mensajes electrónicos dirigidos a perseguir, intimidar, chantajear, apremiar, importunar y vigilar a una mujer que pueda atentar contra su estabilidad emocional, dignidad, prestigio, integridadfísica o psíquica, o quepuedan poner en peligro su empleo, promoción, reconocimiento en el lugar de trabajo o fuera de él".

\section{EL CONCEPTO LEGAL DE ACOSO LABORAL}

Desde el punto de vista del concepto de acoso laboral, es posible determinar que existe una fuerte influencia de la Psicología, en algunos casos porque el legislador la tuvo en cuenta al momento de legislar, o porque en la recepción judicial se utilizan las nociones provenientes de dicho conocimiento.

La ruta parece, salvo ligeras modificaciones, la misma: el uso original de la idea de acoso proviene de las ciencias biológicas, específicamente de los 
estudios del comportamiento de los animales efectuados por Lorenz. De ahí se da un salto al estudio del trabajo de la mano de Ley ma n n, quien lo aplica por primera vez a las organizaciones humanas. Este último lo definió inauguralmente como aquella: "situación en la que una persona ejerce una violencia psicológica extrema, de forma sistemática y recurrente y durante un tiempo prolongado sobre otra persona o personas en el lugar de trabajo con la finalidad de destruir las redes de comunicación de la víctima o víctimas, destruir su reputación, perturbar el ejercicio de sus labores y lograr que finalmente esa persona o personas acaben abandonando el lugar de trabajo"1.

De ahí, la definición de acoso laboral ha pasado al Derecho, ya sea por la vía de las definiciones legislativas, ya sea por la vía de su inclusión como parte de la jurisprudencia que sobre el punto comienza a existir en casi todos los países ${ }^{2}$.

Desde esa perspectiva, el acoso laboral en los pocos países que ha sido expresamente regulado por la ley, ha seguido el camino trazado por la Psicología. Una definición interesante es la del Acuerdo marco europeo sobre violencia y acoso en el trabajo, del año del 2007, donde se le define como aquella situación donde "uno o más trabajadores o directivos son maltratados, amenazados o bumillados, repetida y deliberadamente, en circunstancias relacionadas con el trabajo".

El concepto de acoso laboral ha sido definido, entre otras normas, en el artículo $943 \$ 2$ del Código de Trabajo de Polonia. De conformidad con esta disposición, se entenderá por acoso laboral toda acción o comportamiento, en relación con un empleado o contra el empleado que consiste en un acoso persistente y de larga duración, o en una intimidación de un empleado como resultado de la evaluación decreciente de sus capacidades profesionales, así como el que resulta de la intención de humillar o ridiculizar a un empleado, aislando a él o ella o eliminando a él o ella del equipo de trabajo.

En Francia, la figura es objeto de una doble definición. De acuerdo con el artículo L. 1152-1 del Código de Trabajo, "ningún empleado sufrirá la repetición de actos de acoso que tengan por objeto o por efecto un deterioro de las condiciones de trabajo, que puedan perjudicar sus derechosy su dignidad, la alteración de su salud física o mental o poner en peligro su futuro profesional". Dicha definición fue complementada por la de la Ley de 27 de mayo del

${ }^{1}$ Leymann, Heinz, La persécution au travail (París, Seuil, 1996), p. 18.

${ }^{2}$ Sobre la noción de acoso laboral en la doctrina laboral chilena véanse: GAMOnal Contreras, Sergio - Prado López, Pamela, El “mobbing” o acoso moral laboral, (Santiago, LexisNexis, 2006); y CAAmaño Rojo, Eduardo, La noción de acoso moral laboral o "mobbing" y su reconocimiento por la jurisprudencia en Chile, en Revista de Derecho de la Pontificia Universidad Católica de Valparaiso, 37 ( ${ }^{\circ}$ semestre de 2011), pp. 215-240. 
2008, que asimiló el acoso laboral a una discriminación en relación con la pertenencia o no, real o supuesta, a un grupo étnico, raza, religión, creencias, edad, discapacidad, orientación sexual o de género y cualquier acción de naturaleza sexual sufrida por una persona, cuyo objeto o consecuencia sea la violación de la dignidad o la creación de un entorno hostil, degradante, humillante u ofensivo. Como se advierte, a diferencia de la definición del acoso del artículo L.1152-1 del Código del Trabajo, esta última no requiere de la naturaleza repetitiva de los actos y un acto aislado cuando está vinculada a un motivo discriminatorio, puede ser constitutivo de discriminación.

En Colombia, según el artículo $2^{\circ}$ de la Ley $N^{\circ} 1.010$, de 2006, es acoso laboral "toda conducta persistente y demostrable, ejercida sobre un empleado o trabajador, por parte de un empleador, un jefe o superior jerárquico inmediato o mediato, un compañero de trabajo o un subalterno, encaminada a infundir miedo, intimidación, terror y angustia, a causar perjuicio laboral, generar desmotivación en el trabajo, o inducir la renuncia del mismo".

La posición chilena va contenida en Ley $\mathrm{N}^{\circ} 20.607$, que señala como acoso laboral: "toda conducta que constituya agresión u bostigamiento reiterados, ejercida por el empleador o por uno o más trabajadores, en contra de otro u otros trabajadores, por cualquier medio, y que tenga como resultado para el o los afectados su menoscabo, maltrato o bumillación, o bien que amenace $o$ perjudique su situación laboral o sus oportunidades en el empleo".

\section{Elementos Del acoso laboral DeSDe El Derecho}

Parecería útil en este contexto, ante diversas definiciones de perfiles no siempre coincidentes y con deslindes algo difusos, utilizar la distinción entre el concepto y las concepciones del acoso laboral. De este modo, sobre el concepto común que se maneja en el Derecho del trabajo comparado es posible encontrar, como veremos, diversas concepciones. En ese sentido, más allá de entender una definición en particular como correcta, atendida la dificultad de aprender conceptualmente un fenómeno tan poliforme como el acoso laboral, parece razonable exponer los elementos centrales que en los distintos sistemas jurídicos se ha tenido a la vista al momento de tener que aplicar dicha noción.

Desde esta perspectiva, es posible detectar que, en mayor o menor medida, el diseño de la figura jurídica de acoso laboral ha girado en torno a determinados elementos:

\section{La existencia de una conducta persistente.}

Uno de los requisitos que se incorporó, desde los orígenes de la noción de acoso laboral, es la necesidad de que la conducta sea persistente o recurrente. 
Algunos países lo han acogido explícitamente, como el caso de Colombia o Chile, y otros lo han hecho implícitamente por medio de las elaboraciones jurisprudenciales o doctrinales.

Dentro de los países que incorporan este elemento al concepto, encontramos algunos que lo hacen incluso considerando como parámetro el tiempo señalado por L ey m a n $n$, esto es, que la conducta sea sistemática (al menos una vez por semana) y recurrente (a lo menos durante seis meses).

En Colombia el artículo 2 de la Ley $\mathrm{N}^{\circ} 1.010$, de 2006, señala expresamente que es acoso laboral "toda conducta persistente". En este mismo punto cabe mencionar a Francia, en este país la ley señala la repetición como elemento constitutivo del acoso laboral (el artículo L. 1152-1 del Código de Trabajo).

Pero la eventual rigidez de esta exigencia de repetición ha llevado adoptar cierta flexibilidad frente a conductas graves. En Colombia: la Ley $\mathrm{N}^{\circ} 1.010$, de 2006 señala, en su artículo 7, que: "excepcionalmente un solo acto hostil bastará para acreditar el acoso laboral. La autoridad competente apreciará tal circunstancia, según la gravedad de la conducta denunciada y su capacidad de ofender por si sola la dignidad humana, la vida e integridad fisica, la libertad sexual y demás derechos fundamentales". Y en la misma Francia ya citada luego de la entrada en vigencia de la Ley $\mathrm{N}^{\circ} 27$, de mayo 2008, se incorpora la idea de que un acto aislado -cuando está ligado a un motivo discriminatoriopuede constituir acoso laboral.

En fin, en la misma línea, el artículo artículo 81.18 de la Ley de normas de trabajo del Estado de Québec, en Canadá, establece que: "una sola conducta grave puede también constituir acoso psicológico si supone un daño y produce efecto nocivo continuado para el trabajador".

\section{Que la conducta sea sistemática}

Esto es, que el acoso se verifique por la concurrencia de un conjunto de manifestaciones diversas que degraden, y sean capaces, por su intensidad y sistematicidad, de generar un ambiente laboral vejatorio y humillante.

Una buena parte de la experiencia comparada, como acreditan los informes, ha exigido que el acoso laboral implique una conducta sistémica y compleja, cuestión que se explica por la influencia que en muchos de ellos han tenido los conceptos de la Psicología. Particularmente relevante es la utilización del concepto ya citado de Leyman n que pone acento en este punto de una "situación en la que una persona ejerce una violencia psicológica extrema, de forma sistemática y recurrente y durante un tiempo prolongado sobre otra persona o personas en el lugar de trabajo".

De ese concepto psicológico se tomara la exigencia de "sistematicidad" del acoso, muchos experiencias laborales. El sentido de este elemento es obvio: 
permite distinguir al acoso laboral de situaciones de ordinaria ocurrencia en el trabajo, tales como la falta de compatibilidad entre compañeros de trabajo, tensión laboral, retos, gritos y otros, pero que por su carácter de episodios aislados no permiten sostener la configuración de un acoso laboral propiamente $\mathrm{tal}^{3}$.

Como lo destacará en su oportunidad el propio Le y m a n n "los conflictos son inevitable [...] no estamos hablando aquí sin embargo, del conflicto. Nos referimos a un tipo de situación comunicativa que amenaza con infligir al individuo graves perjuicios psíquicos y físicos. El mobbing es un proceso de destrucción: se compone de una serie de actuaciones hostiles que, tomadas de forma aislada, podrían parecer anodinas, pero cuya repetición constante tiene efectos perniciosos" ${ }^{4}$.

\section{La existencia de una finalidad o intencionalidad determinada.}

La exigencia de un elemento intencional, de carácter subjetivo, en el acoso laboral es una tendencia relevante en el Derecho del trabajo comparado, evidentemente influenciado por las ideas provenientes de la Psicología sobre la materia.

En Polonia se reconoce como finalidad del acoso laboral "bumillar o ridiculizar a un empleado, aislarlo o excluirlo del equipo de trabajo". En Francia, a su turno, el artículo L. 1152-1 del Código de Trabajo, señala que ningún empleado sufrirá la repetición de actos de acoso que tengan "por objeto un deterioro de las condiciones de trabajo, que puedan perjudicar sus derechos y su dignidad, la alteración de su salud física o mental o poner en peligro su futuro profesional".

En ese sentido, para la jurisprudencia mayoritaria de Argentina el acoso laboral tiene "una dirección específica hacia la víctima con una intencionalidad subjetiva y perversa de generar daño o malestar psicológico y el consecuente sometimiento o su egreso de la organización empresarial o del grupo".

La exigencia de un elemento subjetivo o intencionalidad suscita cuestionamientos desde el punto de vista de la doctrina jurídica, sosteniéndose que "podemos estar en presencia aun cuando el sujeto no tenga dicha intención en el plano consciente" tal5.

La impugnación de la intencionalidad ha tenido eco en algunas tradiciones jurídicas. Así en un interesante avance -al menos en términos de la definición- la nueva ley chilena de acoso laboral prescinde expresamente en

${ }^{3}$ CaAmaño Rojo, Eduardo, cit. (n. 2), p. 267.

${ }^{4}$ Leymann, Hanz, cit. (n. 1), p. 26.

${ }^{5}$ Mangarelli, Cristina, El acoso en las relaciones de trabajo, mobbing laboral, en Estudios Laborales, 3 (Sociedad Chilena de Derecho del Trabajo y de la Seguridad Social, 2008), p. 75. 
el texto de cualquier exigencia de un elemento subjetivo en la construcción del tipo del acoso laboral al señalar que lo constituyen las conducta de agresión u hostigamiento que tenga como resultado para el o los afectados su menoscabo, maltrato o humillación, o bien que amenace o perjudique su situación laboral o sus oportunidades en el empleo.

Asimismo, el artículo artículo 81.18 de la Ley de normas de trabajo del Estado de Québec, en Canadá, establece: "se entiende por acoso psicológico una conducta vejatoria que se manifiesta por comportamientos, palabras, actos o gestos repetidos, que son hostiles y no deseados y que supone un daño a la dignidad o la integridad psicológica ofísica del trabajador o que entraña, por si misma, un medio de trabajo nefasto".

\section{El acoso laboral supone la producción de un resultado lesivo a determi-} nados derechos del trabajador

Cualquiera sea la vía de implementación de la noción de acoso laboral -legislativa, jurisprudencial o doctrinal-, este debe producir un resultado lesivo y aquí el punto relevante, no muy destacado en los informes, es determinar qué carácter debe tener ese resultado.

Existe, por una parte, la posibilidad de entender que el acoso laboral requiere un daño síquico determinado y acreditado por la víctima, derivado de la conducta lesiva del victimario, lo que supone, entonces, como cuestión adicional, la prueba tanto de ese daño en concreto, como de la relación de causalidad entre la conducta y el daño.

Pero existe otra opción, que consiste en entender que el resultado lesivo se relaciona con la afectación de uno o varios derechos fundamentales de la víctima y no con un daño síquico en concreto, de modo tal, que lo lesionado es un conjunto de bienes jurídicos protegidos que giran en torno a la dignidad del trabajador, tales como la integridad moral, la honra, la privacidad y la no discriminación.

Es obvio que el tipo de resultado lesivo que se exigirá es una cuestión de política-jurídica, pero con significativas resonancias prácticas, especialmente de naturaleza probatoria para la víctima. Exigir un daño síquico parece más bien, como veremos, una influencia excesiva del mundo de la Psicología sobre el Derecho, ya que desde la perspectiva jurídica parece más relevante la protección de determinados bienes y derechos considerados fundamentales.

\section{LAS CONCEPCiONES DEL ACoSo laboral y EL DeRECho}

Hasta ahora podemos sostener que pese a no existir un reconocimiento legal expreso de modo generalizado para el acoso laboral, ello no ha impedido que la figura haya sido recibida por distintos caminos, especialmente la 
doctrina y la jurisprudencia. En cualquier caso, existe una notoria influencia de la Psicología en la construcción del concepto jurídico de acoso laboral.

Y mas allá de las diversas formulas utilizadas por el derecho para la construcción de la figura del acoso laboral, existe un concepto mínimo y común en la materia - de tratarse de una situación de acoso y hostigamiento de cierta intensidad sobre el trabajador o la víctima-. Sobre ese concepto mínimo se construyen, entonces, las diversas concepciones sobre el acoso laboral en el derecho comparado y que se puede calificar a partir de dos extremos fundamentales, de acuerdo con los elementos configurativos en que se ponga la atención: una subjetiva y otra objetiva.

En la concepción que denominamos subjetiva el acoso laboral se diseña con especial exigencia de elementos de esa índole: la intencionalidad del acosador y la acreditación de un daño síquico a la víctima. Mientras que en el caso de la concepción objetiva, la exigencia fundamental se desplaza a la persistencia y sistematicidad de la conducta del acoso laboral.

De este modo, y ligado con lo anterior, de sostenerse una concepción subjetiva del acoso laboral se hace más acuciante resolver el problema probatorio que el acoso presenta: por una parte, cómo puede la víctima acreditar la existencia de una situación de acoso laboral si ello requiere la prueba de una intencionalidad o elemento subjetivo determinado -el ánimo de excluir o de ofender- $y$, por otra, cómo probar la existencia de un daño síquico y la relación de causalidad respectiva ${ }^{6}$.

El concepto objetivo parece aliviar a la víctima de esos desafíos, pero para ello requiere alejarse de la noción psicológica del acoso laboral y construir una figura con tintes más jurídicos desde una particular perspectiva del derecho: la de los derechos fundamentales.

De hecho, la cuestión central es este punto es sí debe la reflexión jurídica seguir plegada a la noción psicológica de acoso laboral. Es obvio que el derecho no puede prescindir del aporte original que en la construcción de la figura tuvo la Psicología, pero las comunidades jurídicas pueden recorrer su propio camino.

Y ello especialmente porque cada disciplina parece tener su propio afán. En rigor, en la Psicología el problema parece dominar la perspectiva del daño síquico de la victima, pero para el derecho la cuestión parece distinta: la afectación de determinados derechos fundamentales de la victima como son la integridad síquica, la honra, la privacidad y la no discriminación.

Un buen ejemplo del transito de una concepción subjetiva a una objetiva

${ }^{6}$ Ugarte Cataldo, José Luis, Tutela laboral de derechos fundamentales y carga de la prueba, en Revista de Derecho de la Pontificia Universidad Católica de Valparaiso, 33 (2009), pp. 215-228. 
es la reciente ley chilena: ahí se exige más a tono con esta última que la conducta que constituya agresión u hostigamiento sea reiterada y que produzca un resultado lesivo en sentido amplio: "menoscabo, maltrato o bumillación, o bien que amenace o perjudique su situación laboral o sus oportunidades en el empleo".

En la Ley $\mathrm{N}^{\circ} 20.607$ no se exige ni intención, ni un daño síquico en concreto.

\section{Consideraciones finales}

Como es fácil de advertir de lo todo lo expuesto antes, la cuestión central en torno el tema del concepto del acoso laboral es si el Derecho debe seguir plegado a la noción psicológica.

Es bastante obvio que el Derecho no puede prescindir del aporte original que en la construcción de la figura tuvo la Psicología, pero las comunidades jurídicas tienen el deber de cuestionar cuál es el mejor modo de proteger a los trabajadores y sus derechos fundamentales, todo en torno al objetivo constitutivo del Derecho del Trabajo: la protección del trabajador. En ese sentido, y visto lo expuesto antes, parece razonable sostener que debería transitarse desde una traslación automática del concepto de acoso laboral, a una relación reflexiva de la interacción entre Psicología y Derecho del trabajo. Especialmente reflexiva en torno a la construcción de la noción de acoso laboral en torno a dos cuestiones fundamentales: primero, qué elementos deben ser considerados en la construcción del tipo de acoso laboral que se quiere reprimir, y segundo, la conveniencia de construir un ilícito de actividad o en cambio, de resultado.

Respecto de lo primero es especialmente relevante analizar críticamente los diversos elementos que, como se explico, son exigidos por la Psicología para la construcción de la figura del acoso laboral, lo cual atañe particularmente a la exigencia de reiteración, a la de intencionalidad -el elemento subjetivo- y al resultado lesivo. Es perfectamente lícito que el Derecho haga una recepción critica de los elementos que constituyen el acoso laboral, atendiendo a razones de política legislativa, especialmente aquellas que permitan, como se explico, transitar de una concepción recargada de elementos subjetivos de difícil alcance por la victima, a una concepción objetiva que facilite la acreditación del acoso.

Respecto de los segundo, es necesario revisar si debe mantenerse la tendencia de diseñar tipo de ilícitos que ponen el acento en la actividad del sujeto acosador, más que en el resultado de la afectación de los derechos fundamentales de la victima. En rigor, para la Psicología el problema parece ser el daño síquico de la victima; para el Derecho la afectación de determi- 
nados derechos fundamentales asociados a la integridad moral como son la integridad síquica, la honra, la privacidad y la no discriminación. Hay conductas humillantes e invasivas que, aun cuando no se traduzcan en un daño físico significativo, pueden ser ilícitas para el derecho por la lesión de un bien o derecho fundamental como la integridad moral u otro.

La creación de un tipo del acoso laboral suponen la creación de un ilícito laboral que describa el fenómeno y lo conecte con una sanción prevista por el derecho: indemnizaciones, nulidad, multas, etc. En ese punto, la cuestión es obvia: qué hacer con los casos fácticos relevantes que quedaran fuera del tipo -esto es, de la descripción legal-y que suponen de igual modo la afectación de bienes relevantes para el sistema. Ante este dilema, una posibilidad para el Derecho del trabajo es la protección mirando los resultados: la conducta no es el acoso laboral propiamente tal, sino aquellas conductas que lesionan derechos fundamentales de los trabajadores afectados, tales como la integridad física o síquica, no discriminación, honra y/o privacidad.

\section{BIBLIOGRAFÍA}

CAAMAÑo Rojo, Eduardo, La noción de acoso moral laboral o "mobbing” y su reconocimiento por la jurisprudencia en Chile, en Revista de Derecho de la Pontificia Universidad Católica de Valparaíso, 37 (2011).

Gamonal Contreras, Sergio - Prado López, Pamela, El “mobbing” o acoso moral laboral (Santiago, LexisNexis, 2006).

Leymann, Heinz, La persécution au travail (París, Seuil, 1996).

Mangarelli, Cristina, El acoso en las relaciones de trabajo, "mobbing” laboral, en Estudios Laborales, 3 (Sociedad Chilena de Derecho del Trabajo y de la Seguridad Social, 2008).

Ugarte Cataldo, José Luis, Tutela laboral de derechos fundamentales y carga de la prueba, en Revista de Derecho de la Pontificia Universidad Católica de Valparaíso, 33 (2009). 
